\title{
Mechanical stability of filaments for ITER Diagnostic Pressure Gauges relating to creep and fatigue
}

\author{
Alexey Arkhipov, Felix Mackel, Günter Haas, Jürgen Koll, Hans Meister, Fabien Seyvet, \\ Santiago Terron and Philip Andrew
}

\begin{abstract}
Diagnostic Pressure Gauges (DPGs) shall provide measurements of the neutral gas pressure in various locations of the ITER vacuum vessel. This parameter is essential for the basic control of ITER operation as well as for input to physics models of the plasma boundary. The hot cathode (filament) is the component of the DPG sensor that is exposed to most demanding loads. In order to reach the required electron emission from the filament, it has to be heated to high temperatures by a direct current. As a result, thermal stresses appear and, in the presence of a magnetic field, additional mechanical stresses caused by Lorentz forces arise. On the one hand, due to a large number of pulses foreseen in ITER this load will be cyclic, which may result in filament failure caused by fatigue. On the other hand, longest pulses in ITER are expected to be in the order of 30 minutes and, thus, filaments could fail due to creep. In order to verify that the filament of the DPG sensor can withstand fatigue and creep dedicated experiments have been conducted. Results of these tests are discussed in this paper.
\end{abstract}

Index Terms-creep, fatigue, ITER, plasma diagnostic, pressure gauge, tungsten filament.

\section{INTRODUCTION}

$\mathrm{T}$ HE operational time of a single gauge is limited by the filament lifetime, which depends on many parameters, in particular, on filament material and geometry and operational conditions. Experience with operation of ASDEX pressure gauges (APGs) [1], which is a basic technology for ITER DPGs [2], in W7-X and JET showed that mean time to failure (MTTF) of the filament sometimes is in the order of tens of hours. For ITER, however, this time should be much longer in order to fulfil the requirement of $98 \%$ system availability over the expected 20 years of ITER operation. Thus, assuming the filament lifetime as 1500 hours and taking into account that only gauges located in the divertor level will be replaced once, the diagnostic shall include 52 gauges. More gauges would allow to reduce operational time of a single gauge but

This work was partly supported by Fusion for Energy under the Specific Grant F4E-FPA-364-SG05.

Alexey Arkhipov, Felix Mackel, Günter Haas, Jürgen Koll and Hans Meister are with Max-Planck Institute for Plasma Physics, Boltzmannstraße 2, D-85748 Garching, Germany (e-mail: alexey.arkhipov@ipp.mpg.de)

Fabien Seyvet and Santiago Terron are with Fusion for Energy, C/Josep Pla, $\mathrm{n}^{\circ}$ 2, Torres Diagonal Litoral, Edificio B3, 08019 Barcelona, Spain installation of extra items is not possible due to space limitation in ITER locations where DPGs will be placed. Therefore, the most challenging goal in the development of ITER DPGs is to find suitable design solution for the filament which can provide the operation of a single gauge minimum during 1500 hours corresponding to $3000 \mathrm{on} / \mathrm{off}$ cycles.

The filament in a baseline design of the DPG head has a three-dimensional shape with 2 spirals [2] which are stressed by a retention force to hold the horizontal part of the filament in place. The cumulative force of this section is acting with a lever arm which leads also to a torsional stress in the wire. Practical experience as well as performed finite element (FE) analysis [3] shows that this zone is the weakest part of the filament. Accordingly, the deformation leads to a movement of the filament towards the control electrode. Eventually, the filament touches the electrode leading to a gauge malfunction.

Repeated on/off cycles of the gauge in a magnetic field can lead to a fatigue of the filament material resulting in failure. It is also suspected that creep - slow material deformation under stress, where strain rates are highly dependent on the operating temperature, might be an issue ${ }^{1}$. Both fatigue and creep are complex interconnected processes that incorporate many material properties which are not known a priori. Information available in public literature is not enough for reliable theoretical assessments. Thus, it is desirable to gain fatigue and creep data of chosen filament material by dedicated tests. The experimental approach taken to verify the fatigue and creep behavior of DPG prototypes is described in the following sections.

\section{FilAment FAtigue}

\section{A. Approach for Testing}

A failure due to fatigue can be described only by statistics since scattering of the results could be high. One possibility is to perform a so-called "accelerated fatigue test" commonly

Philip Andrew is with ITER Organization, Route de Vinon-sur-Verdon, CS 90 046, 13067 St. Paul Lez Durance Cedex, France

${ }^{1} \mathrm{~A}$ measurement of the temperature profile along the filament [3] showed that in some cases the temperature of the hottest part of the filament could reach roughly about $60 \%$ of the melting point of tungsten. 
used in industry when an increased load is applied. This approach was not chosen since an increase of the magnetic field is not possible due to limitations on the magnet operation while an increase of the heating current is known to destroy the filament coating needed to reduce the work function of electrons. Thus, either it has to be demonstrated that a large number of gauges survive the demanded cycles in a magnetic field of the same flux density as in ITER or a single gauge survives for a much larger number of cycles - at the minimum 10 times more than the number of required operational cycles. Since the latter approach requires significant testing time in the laboratory it was decided to perform the required 3000 on/off cycles for a maximum number of filament samples, which can be accommodated inside the experimental setup.

A dedicated test has been performed in the facility JUMBO located in Karlsruhe Institute of Technology (KIT) (see Fig. 1). The facility is equipped with a magnet which is able to produce magnetic fields of up to $10 \mathrm{~T}$ at the middle part of the magnet bore [4]. The magnet itself consists of superconducting $\mathrm{NbTi}$ and $\mathrm{Nb}_{3} \mathrm{Sn}$ coils cooled in liquid Helium bath [4]. Additionally, a cryostat is installed in the bore of the magnet to conduct experiments at temperatures up to room temperature.

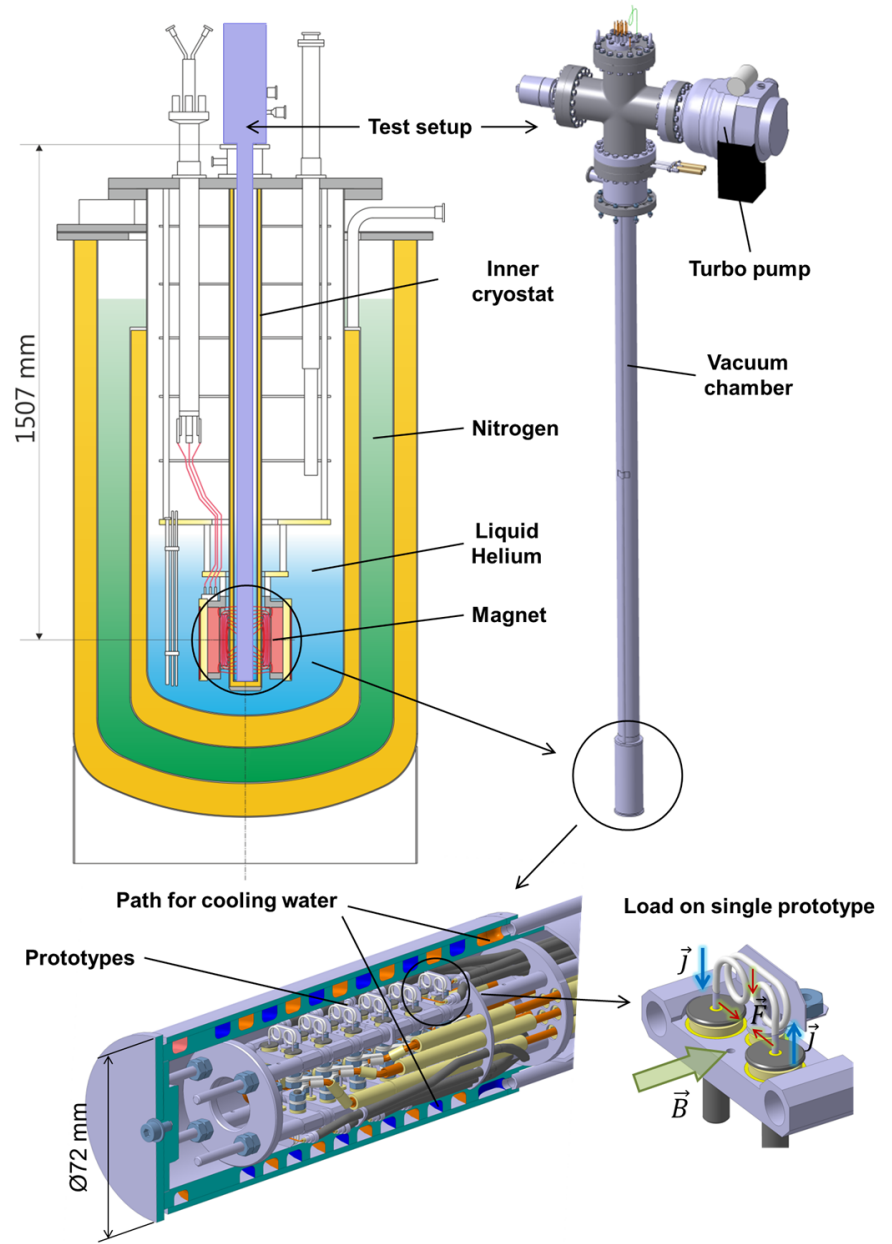

Fig. 1. Scheme of the facility JUMBO (left) and model of experimental setup for fatigue testing of DPG prototypes (right).

Since the space providing the high field volume in the magnet is restricted, a maximum of 12 prototypes could be tested (see Fig. 1). Taking into account that the number of tested cycles is equal to the number of operational cycles, the desired value of reliability is 0.9 and assuming a constant failure rate over the operational time $(\beta=1)$, the expected confidence in the test results is $\sim 72 \%$ according to the following relation [5]:

$C=1-R^{\left(n_{1}\right)\left(t_{1} / t_{2}\right) \beta}$,

where $\mathrm{C}$ - confidence, $\mathrm{R}$ - reliability, $\mathrm{n}_{1}$ - number of tested specimens, $t_{1}-$ number of tested cycles, $t_{2}-$ number of real operation cycles and $\beta$-Weibull failure rate distribution slope.

A photograph of a single DPG prototype is shown in Fig 2.

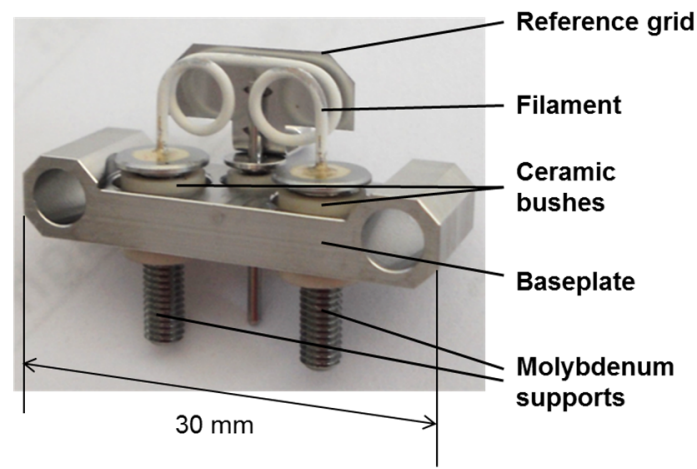

Fig. 2. Photograph of DPG prototype for fatigue test.

The spiral filament made of Tungsten-Rhenium wire with a diameter of $0.8 \mathrm{~mm}$ and coated with Yttrium oxide is brazed to the molybdenum supports which are insulated from the baseplate by alumina bushes. Fixation of supports and insulators is also done by brazing. The reference grid in front of the filament acts as a detector in case of filament failure. An electrical short can be detected immediately from the outside.

All prototypes are placed in the experimental setup, specially developed for this investigation, which was then inserted into the inner cryostat of the JUMBO facility (see Fig. 1). In order to prevent the impact of the total heat produced by the hot filaments onto the magnet, which might cause the magnet to quench, the setup was cooled during the experiment by water flow. In addition, for better thermal insulation, air was evacuated between the inner cryostat and the experimental setup. The temperature of the experimental setup was controlled by means of a thermocouple installed in the base plate of one prototype in the center of the assembly. The pressure inside the vacuum chamber of the experimental setup was controlled by means of the commercial Baratron. It was assumed to stop the test immediately in case of a temperature or a pressure rise.

Prototypes were accommodated in the experimental setup in such a way that forces act similar for each prototype - the electrical connections for feeding the heating current are chosen such that the resulting local force vectors point "inwards" for each filament (see Fig. 1). Filaments have been connected in series but with the opportunity to bridge each damaged filament outside the vacuum chamber. Thus, the experiment does not need to be stopped in case one filament fails. 


\section{B. Testing Procedure}

Filaments were fed by 2 power supplies -1 power supply per 6 prototypes with a heating current of $17 \mathrm{~A}$. This value was chosen based on results of previously performed tests $[6,7]$. The cycles defined included filament heating and cooling phases, both of the same duration, which was optimized so that filaments were in a thermal equilibrium at the end of each phase:

1. $0 \mathrm{~s}-1 \mathrm{~s}: 0.5 \mathrm{~A} \rightarrow 17 \mathrm{~A}$, linear increase

2. $1 \mathrm{~s}-39 \mathrm{~s}: 17 \mathrm{~A}$ constant

3. $39 \mathrm{~s}-40 \mathrm{~s}: 17 \mathrm{~A} \rightarrow 0.5 \mathrm{~A}$, linear decrease

4. $40 \mathrm{~s}-80 \mathrm{~s}: 0.5 \mathrm{~A}$ constant

The calculated temperature in the center of the filament is shown in Fig. 3.

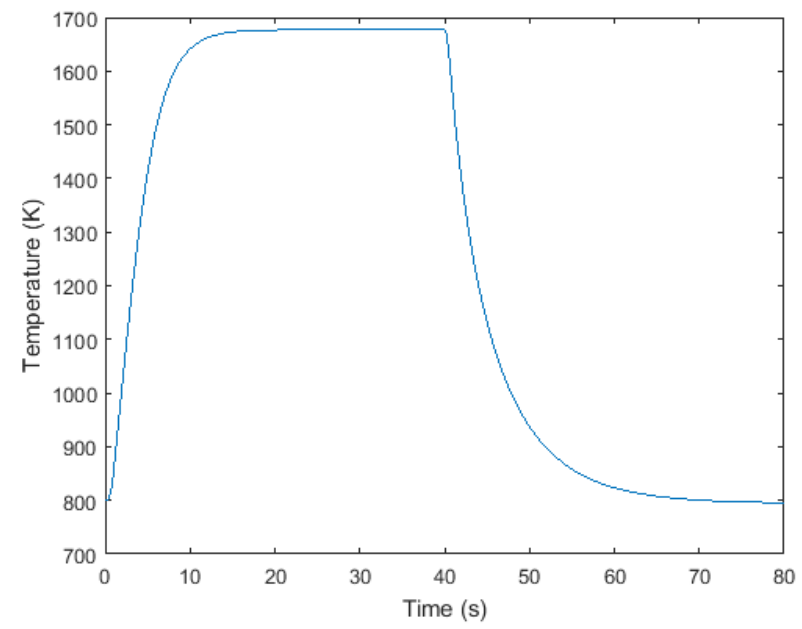

Fig. 3. Change of temperature in the center of the filament during 1 cycle.

The baseline current of $0.5 \mathrm{~A}$ serves to measure the voltage drop across the filaments during cooling phase to get a value of total resistance which is used for rough estimation of the mean filament temperature. This is important for post-analysis of possible failures. At the same time, the heating current of $0.5 \mathrm{~A}$ does not lead to a significant power load to the filaments.

3000 on/off cycles have been executed while the prototypes were exposed to a steady state magnetic field of $8 \mathrm{~T} \pm 5 \%$ which is of the same magnitude as expected in the most demanding locations in ITER.

The experiment was controlled in an automatized way by a LabView program. Data acquisition and control of test equipment was done using a I/O-PCIe card from National Instruments. The waveform of the current was reproduced exactly as defined above and recorded.

\section{Results}

All 12 prototypes survived 3000 on/off cycles. During the test no shorts between filaments and reference grids were detected. Inspection after the test showed that neither filament nor brazing at any of the 12 tested prototypes were damaged.

In order to gain some realistic creep data after repeated startups the filament samples were heated under magnetic field of $8 \mathrm{~T}$ for 16 hours continuously: 6 filaments at $18 \mathrm{~A}$ and 6 filaments at $22 \mathrm{~A}$. No indication of deformation of any filament operated at $18 \mathrm{~A}$ was observed, whereas some samples operated at $22 \mathrm{~A}$ were deformed as shown in Fig. 4. The average deflection rate for 3 deformed filament samples is $\sim 26 \mu \mathrm{m} / \mathrm{h}$.
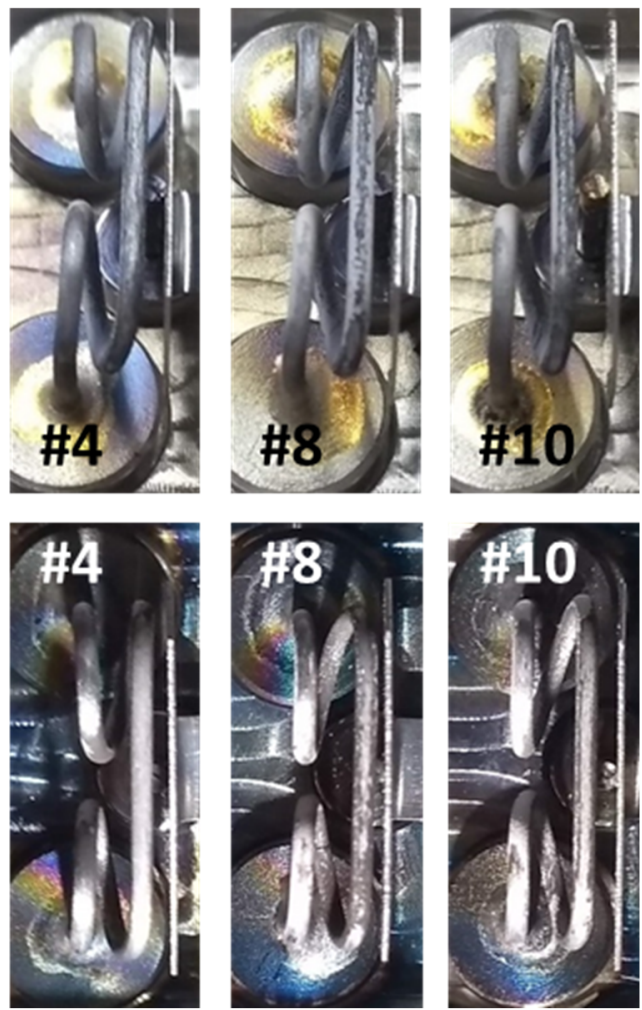

Fig. 4. Photographs of filament samples after 3000 repeated start-ups (top row) and after an additional 16 hours of continuous operation under magnetic field of $8 \mathrm{~T}$ at a heating current of $22 \mathrm{~A}$ (bottom row) ${ }^{2}$.

\section{FILAMENT CREEP}

\section{A. Approach for Testing}

Creep tests on a timescale of hundreds of hours are not feasible in high magnetic fields without superior effort. Instead, $\vec{J} \times \vec{B}$ forces acting on the filament during operation of the gauge and which are distributed over the whole filament length (see Fig. 5, left) can be mimicked in a creep test by a point force created by an attached weight (see Fig 5 , right) with a mass calculated according to:

$m_{\text {tot }}=I \cdot B \cdot l_{\text {hor }} / g$,

where I - heating current, B - magnetic field, $l_{\text {hor }}$ - horizontal length of the filament, and $\mathrm{g}$ - gravitational acceleration. 

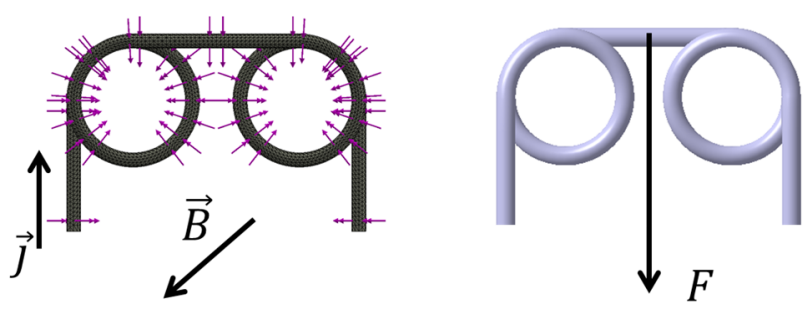

Fig. 5. Illustration of forces acting on filament in operation (left) and in creep test (right).

For instance, a heating current of $25 \mathrm{~A}$ in a magnetic field of $8 \mathrm{~T}$ causes a force per unit length of $200 \mathrm{~N} / \mathrm{m}$ or $2 \mathrm{~N}$ on the horizontal part of the filament with $1 \mathrm{~cm}$ length. This can be mimicked by a weight with a mass of $200 \mathrm{~g}$ attached to the center of the filament.

To check whether this approximation is accurate enough to replicate $\vec{\jmath} \times \vec{B}$ forces, results of $\mathrm{FE}$ analysis for the filament loaded by $\vec{\jmath} \times \vec{B}$ forces and by a point force have been compared.

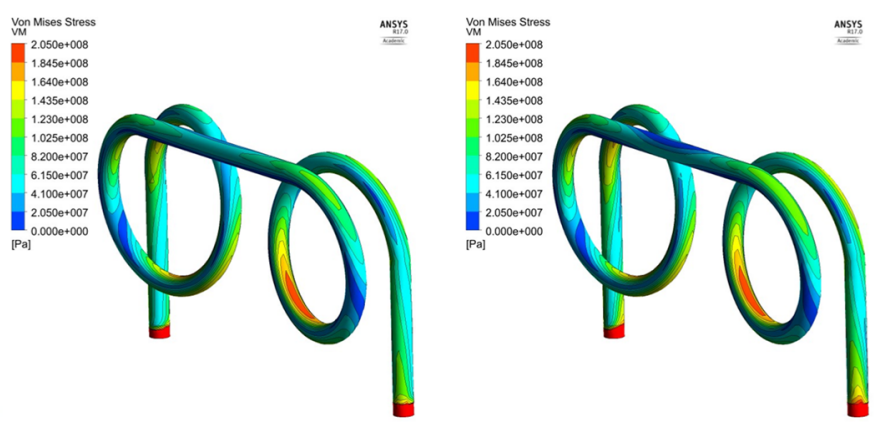

Fig. 6. Distribution of Von Mises stress in a filament under $\vec{\jmath} \times \vec{B}$ force as expected in operation (left) and under the load of an equivalent point force (right) for the load case of 25 A @ 8 T.

As shown in Fig. 6 the stress distribution in both cases is similar, while to achieve the same maximum stress as for the real force distribution, a vertical load of $1.65 \mathrm{~N}$ corresponding to a mass of $165 \mathrm{~g}$ shall be applied. Even though equation (2) gives conservative values it was used for calculating masses of the weights used to mimic various load cases in creep test.

\section{B. Testing Procedure}

Creep tests of several filament samples have been conducted at IPP in the vacuum facility of the neutral gas laboratory (see Fig. 7). Filament samples were mounted onto specific prototype gauges and fixed by screws. The weight replicating the $\vec{\jmath} \times \vec{B}$ force was hanged to the middle of the horizontal part of the filament by means of a thin tungsten wire with a diameter of $0.25 \mathrm{~mm}$.

\footnotetext{
${ }^{3}$ For all test cases a mass of the attached weight was calculated for a magnetic field of $8 \mathrm{~T}$ which is expected in most demanding locations in ITER.
}

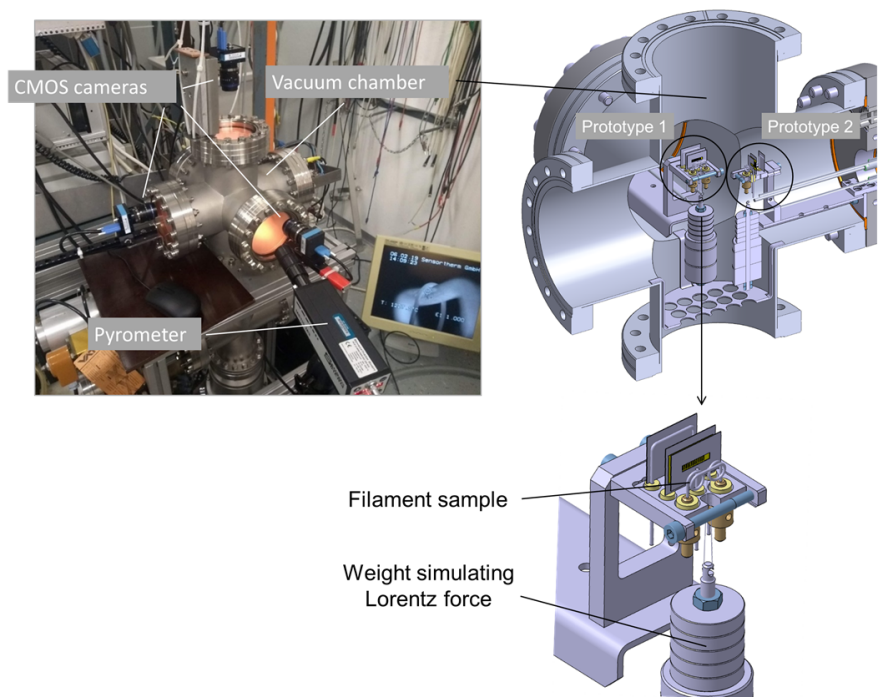

Fig. 7. Experimental setup for creep test of filament samples.

After the installation of prototypes and attachment of weights ${ }^{3}$ to the filaments the vacuum chamber was pumped by a turbo pump until the pressure reached $<10^{-5} \mathrm{~Pa}$. Then filaments were fed by the DC current in a feedforward mode.

To pass the test successfully the filament had to survive a minimum 1500 hours without deflection of its horizontal part to more than $1 \mathrm{~mm}$ in horizontal direction. This corresponds in a real gauge to the filament touching the control electrode.

In order to optimize the experimental time in the laboratory the setup was designed to test 2 filament samples in parallel in the same vacuum chamber. During experiment both tested samples were observed continuously from the top, the front and the side perspectives by a camera through a lateral window. To detect the deformation of filament samples photographs from each perspective were taken every 30 minutes.

\section{Results}

In total 4 filament samples with a spiral shape and a diameter of $0.8 \mathrm{~mm}$ have been tested ${ }^{4}$. The results are summarized in Table 1.

Table 1. Results of creep test.

\begin{tabular}{|c|c|c|c|c|c|}
\hline \# & $\begin{array}{l}\text { Tested } \\
\text { filament } \\
\text { sample }\end{array}$ & $\begin{array}{l}\text { Load } \\
\text { case }\end{array}$ & $\begin{array}{l}\text { Mass of } \\
\text { attached } \\
\text { weight and } \\
1_{\text {hor }} \\
\end{array}$ & $\begin{array}{l}\text { Deflection } \\
\text { rate in } \\
\text { hor./vert. } \\
\text { direction } \\
\end{array}$ & $\begin{array}{l}\text { Time to } \\
\text { failure }\end{array}$ \\
\hline 1 & $\begin{array}{l}\mathrm{W}-26 \% \mathrm{Re}+ \\
\mathrm{Y}_{2} \mathrm{O}_{3} \text { coating }\end{array}$ & $\begin{array}{l}22 \mathrm{~A} \\
\text { (a) } 8 \mathrm{~T}\end{array}$ & $\begin{array}{l}176 \mathrm{~g} \\
10 \mathrm{~mm}\end{array}$ & $\begin{array}{l}\sim 50 \mu \mathrm{m} / \mathrm{h} \\
\sim 145 \mu \mathrm{m} / \mathrm{h}\end{array}$ & $\sim 20 \mathrm{~h}$ \\
\hline 2 & $\begin{array}{l}\mathrm{W}-26 \% \mathrm{Re}+ \\
\mathrm{Y}_{2} \mathrm{O}_{3} \text { coating }\end{array}$ & $\begin{array}{l}18 \mathrm{~A} \\
\text { @ } 8 \mathrm{~T} \\
\end{array}$ & $\begin{array}{l}145 \mathrm{~g} \\
10 \mathrm{~mm} \\
\end{array}$ & $\begin{array}{l}\sim 10 \mu \mathrm{m} / \mathrm{h} \\
\sim 14 \mu \mathrm{m} / \mathrm{h} \\
\end{array}$ & $\sim 100 \mathrm{~h}$ \\
\hline 3 & $\begin{array}{l}\mathrm{W}-70 \mathrm{ppmK}- \\
1 \% \mathrm{ThO}_{2}+ \\
\mathrm{Y}_{2} \mathrm{O}_{3} \text { coating }\end{array}$ & $\begin{array}{l}24 \mathrm{~A} \\
\text { (a) } 8 \mathrm{~T}\end{array}$ & $\begin{array}{l}192 \mathrm{~g} \\
10 \mathrm{~mm}\end{array}$ & $\begin{array}{l}\sim 1 \mu \mathrm{m} / \mathrm{h} \\
\sim 3 \mu \mathrm{m} / \mathrm{h}\end{array}$ & $\sim 350 \mathrm{~h}$ \\
\hline 4 & $\begin{array}{l}\mathrm{W}-70 \mathrm{ppmK}- \\
1 \% \mathrm{ThO}_{2}+ \\
\mathrm{Y}_{2} \mathrm{O}_{3} \text { coating }\end{array}$ & $\begin{array}{l}24 \mathrm{~A} \\
\text { (a) } 8 \mathrm{~T}\end{array}$ & $\begin{array}{l}154 \mathrm{~g} \\
8 \mathrm{~mm}\end{array}$ & $\begin{array}{l}<<1 \mu \mathrm{m} / \mathrm{h} \\
<<1 \mu \mathrm{m} / \mathrm{h}\end{array}$ & $>1700 \mathrm{~h}$ \\
\hline
\end{tabular}

${ }^{4}$ Filaments made of throated tungsten which are used in ASDEX pressure gauges [1] were not tested since after investigations described in [7] this material is not considered for ITER DPGs. 
At first, filaments made of Tungsten-Rhenium alloy, samples 1 and 2, have been examined. The values of the applied heating current were chosen based on results of performance testing of DPG prototypes with the same filament [6]: for sample $122 \mathrm{~A}$ were applied to simulate the maximum current required, for sample $218 \mathrm{~A}$ were applied to simulate the average current during operation. Both samples failed the test after $\sim 20 \mathrm{~h}$ and $\sim 100$ h respectively.

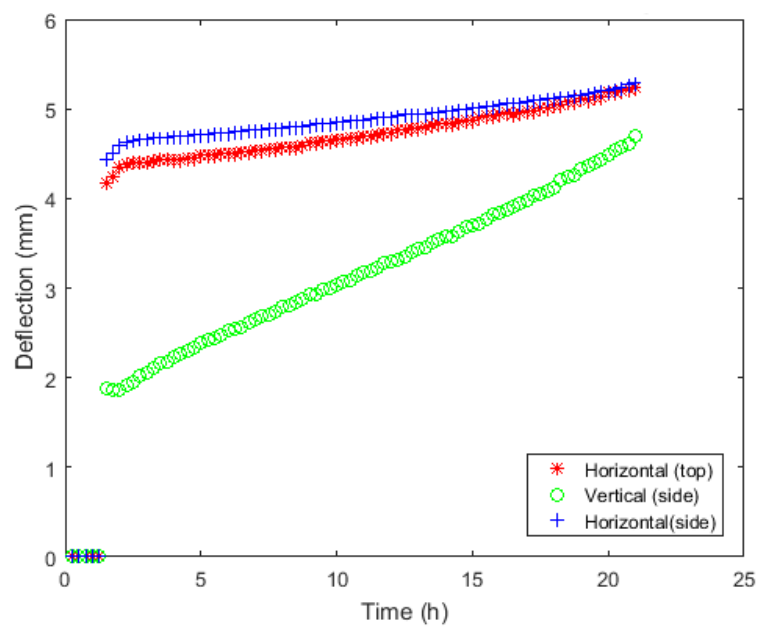

Fig. 8. Creep rate of the filament sample made of Tungsten-Rhenium wire with a diameter of $0.8 \mathrm{~mm}$ heated by a current of $22 \mathrm{~A}$ and attached weight with a mass of $176 \mathrm{~g}$.

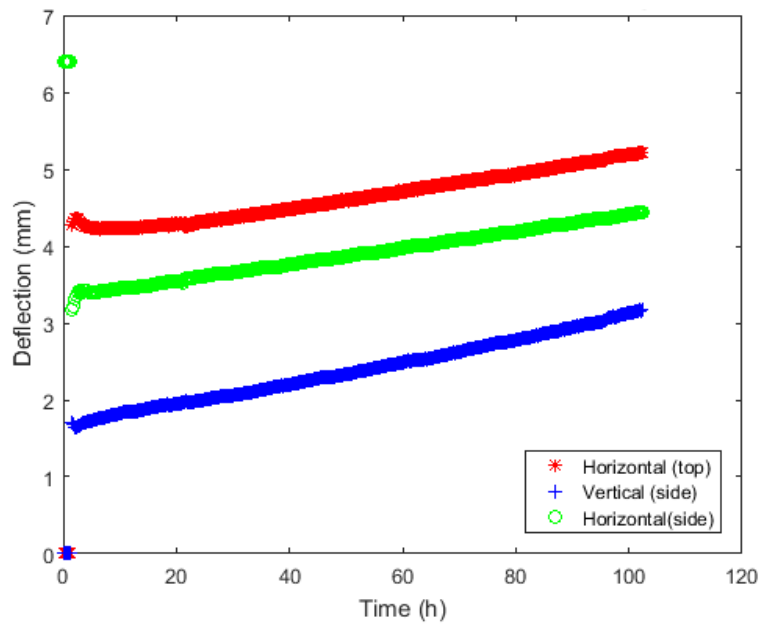

Fig. 9. Creep rate of the filament sample made of Tungsten-Rhenium wire with a diameter of $0.8 \mathrm{~mm}$ heated by a current of $18 \mathrm{~A}$ and attached weight with a mass of $145 \mathrm{~g}$.

In both cases the deflection rate was constant over the time as shown in Fig. 8 and Fig. 9. This parameter, however, is worse than observed during testing in real magnetic field at KIT (see Section 2C). This in addition confirms the conclusion that masses of weights for replication of Lorentz forces calculated by formula (2) are conservative.

As a next step, filaments made of Tungsten doped with

${ }^{5}$ Temperature measurement was done by means of a 1-color radiation pyrometer Metis M313. Both samples are coated with the same material $-\mathrm{Y}_{2} \mathrm{O}_{3}$, of which the emissivity is not known. However, measurement conditions in both cases were identical, i.e. transmissivity of the window, dimensions of
Potassium have been tested. This material has better strength under creep than the tungsten rhenium alloy but less electrical resistivity. For a proper comparison with sample 2, the heating current of sample 3 has been increased up to $24 \mathrm{~A}$ in order to achieve the same surface temperature 5 . The test showed that under equivalent load sample 3 was running $\sim 350$ hours before failure, which is 3.5 times longer than sample 2 but still 4.2 times shorter than required.

Sample 4 was tested under the same heating current as sample 3, namely $24 \mathrm{~A}$, but attached weight had a smaller mass corresponding to a length of the filament horizontal part of $8 \mathrm{~mm}$ in equation (2). Although the load in this case is less conservative it reproduces the real force better ${ }^{6}$. Under this load sample 4 was running more than 1700 hours without distinct deformation as can be seen in Fig. 10.
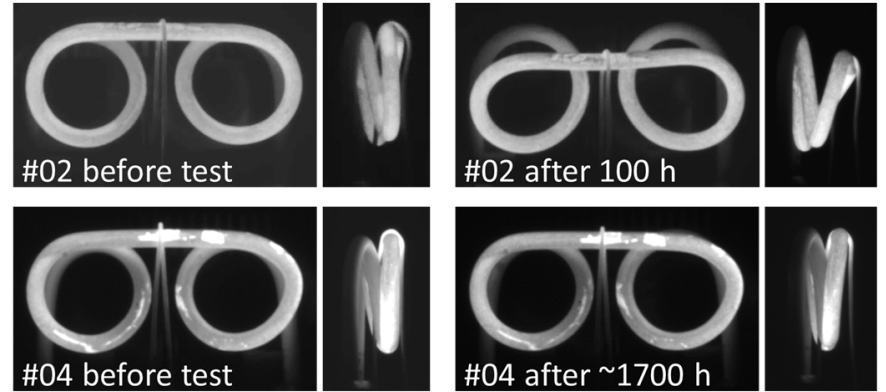

Fig. 10. Photographs of filament sample \#2 made of Tungsten-Rhenium wire and filament sample \#4 made of Tungsten doped with Potassium before and after creep test.

\section{CONCLUSION AND FutURE WORK}

The tests performed demonstrated that fatigue is not a problem, neither for filament nor for brazing, and, accordingly, DPGs in ITER will survive 3000 operational cycles. However, creep is a serious issue at least for filaments with a spiral shape.

Up to now the bending of filaments into this shape could not be controlled to reproduce exactly the same shape for each sample; even minor deviations from the initial design might increase the deflection rate and reduce the time to failure. It can also be concluded that filaments made of Tungsten doped with Potassium have a much better resistance against creep. On the other hand, to reach stable electron emission, these filaments have to be heated with quite high currents, which is an obvious drawback.

Although the loads applied to the filament during creep tests are similar to the real $\vec{\jmath} \times \vec{B}$ forces, the latter aren't represented exactly. Thus, to be on the safe side, one should aim to larger safety margins. To this end, future work will be concentrating first on optimizing the shape. In particular, it is expected that filaments with a planar shape will be more creep resistant than filaments with a spiral shape as examined within this work.

sample and distance to the object. Thus, light intensities have been compared instead of values of absolute temperature.

${ }^{6} \mathrm{~A}$ mass of the weight calculated by equation (2) for the load case described in Section $3 \mathrm{~A}, \mathrm{I}=25 \mathrm{~A}$ and $\mathrm{B}=8 \mathrm{~T}$ but assuming $\mathrm{L}_{\text {hor }}=8 \mathrm{~mm}$, would be $160 \mathrm{~g}$ which is close to a value of $165 \mathrm{~g}$ resulting from $\mathrm{FE}$ analysis. 
An additional approach will be to investigate other types of electron emitters for the use in ITER, e.g. crystal emitters with indirect heating, which require significantly less heating current for the same electron emission. At present pressure gauges with such emitters are in operation at W7-X [8].

\section{ACKNOWLEDGMENT}

The views expressed in this publication are the sole responsibility of the authors and do not necessarily reflect the views of the Fusion for Energy and the ITER Organization.

Neither Fusion for Energy nor any person acting on behalf of Fusion for Energy is responsible for the use, which might be made of the information in this publication.

The Authors would like to thank the technical team of Institute for Technical Physics (ITEP) of Karlsruhe Institute of Technology (KIT) and especially Frank Hornung and Theo Schneider for their help in preparing and executing the fatigue test.

\section{REFERENCES}

[1] G. Haas, H.S. Bosch, Vacuum 51 (1998) 39-46

[2] A. Arkhipov et al, Fus. Eng. Des. DOI: 10.1016/j.fusengdes.2016.12.020

[3] A. Arkhipov et al, Fus. Eng. Des. DOI: 10.1016/j.fusengdes.2018.02.062

[4] A. Rimikis et al, IEEE Trans. Appl. Supercond. DOI: 10.1109/77.828536

[5] Y. Lee et al, Fatigue Testing and Analysis. DOI: 10.1016/B978-0-75067719-6.X5000-3

[6] F. Mackel et al, Fus. Eng. Des. DOI: 10.1016/j.fusengdes.2019.01.038

[7] A. Arkhipov et al, Fus. Eng. Des. DOI: 10.1016/j.fusengdes.2019.02.054

[8] U. Wenzel et al, Rev. Scient. Instr. DOI: 10.1063/1.5019765 